\title{
Suspension settings for optimal ride comfort of off-road vehicles travelling on roads with different roughness and speeds
}

\author{
P.E. Uys ${ }^{\mathrm{a}}$, P.S. Els ${ }^{\mathrm{a}}$ and M. Thoresson ${ }^{\mathrm{a}}$ \\ ${ }^{\mathrm{a}}$ Department of Mechanical and Aeronautical Engineering, University of Pretoria, \\ Pretoria 0002, South Africa
}

\section{Abstract}

This paper reports on an investigation to determine the spring and damper settings that will ensure optimal ride comfort of an off-road vehicle, on different road profiles and at different speeds. These settings are required for the design of a four stage semi-active hydro-pneumatic spring damper suspension system $\left(4 \mathrm{~S}_{4}\right)$. Spring and damper settings in the $4 \mathrm{~S}_{4}$ can be set either to the ride mode or the handling mode and therefore a compromise ride-handling suspension is avoided. The extent to which the ride comfort optimal suspension settings vary for roads of different roughness and varying speeds and the levels of ride comfort that can be achieved, are addressed. The issues of the best objective function to be used when optimising and if a single road profile and speed can be used as representative conditions for ride comfort optimisation of semi-active suspensions, are dealt with. Optimisation is performed with the Dynamic-Q algorithm on a Land Rover Defender 110 modelled in MSC.ADAMS software for speeds ranging from 10 to $50 \mathrm{~km} / \mathrm{h}$. It is found that optimising for a combined driver plus rear passenger seat weighted root mean square vertical acceleration rather than using driver or passenger values only, returns the best results. Results indicate that optimisation of suspension settings using one road and speed will improve ride comfort on the same road at different speeds. These settings will also improve ride comfort for other roads at the optimisation speed and other speeds, although not as much as when optimisation has been done for the 
particular road. For improved ride comfort damping generally has to be lower than the standard (compromised) setting, the rear spring as soft as possible and the front spring ranging from as soft as possible to stiffer depending on road and speed conditions. Ride comfort is most sensitive to a change in rear spring stiffness.

\section{Article Outline}

1. Introduction

2. Deciding on the best objective function

3. Measured results

4. Road profiles

5. Determining optimal suspension settings

5.1. The simulation model

5.2. The optimisation procedure

6. Results

6.1. Optimal suspension settings for different roads and speeds

6.2. Using optimisation results for one road at a particular speed

6.3. Sensitivity of ride comfort to spring and damper adjustments

7. Conclusions

Acknowledgements

References

\section{Introduction}

Numerous studies have been conducted on the description and improvement of ride comfort. To this end parameters, indicative of ride comfort (e.g. vertical acceleration, absorbed power), have been described and levels of acceptance laid down in standards such as ISO 2631-1 [1], BS 6841[2] and VDI 2057 [3]. With the introduction of active and semi-active suspensions, these criteria for acceptability have been applied in control systems to determine suspension settings to obtain required levels of ride comfort. Most applications have been for highway travelling in luxury cars equipped with adjustable dampers. In recent research, the focus has turned to ride comfort of off-road vehicles. 
This paper deals with the ride-comfort suspension settings required for off-road conditions. A full-3D model of a Land Rover Defender previously developed in the dynamic simulation package MSC.ADAMS [4], and verified against track tests, is used in the investigation.

The aim of the investigation is to determine the spring and damper settings that will ensure optimal ride comfort on different road profiles and at different speeds. These results are to be incorporated into a four stage semi-active hydro-pneumatic springdamper system currently being developed at the University of Pretoria. Two settings are available in this semi-active suspension system - one chosen to provide optimal ride comfort and the other to provide optimum handling. The question arises: to what extent do the optimal suspension settings vary for a road of given roughness if traversed at different speeds and what levels of ride comfort can be achieved in these cases? The other question to be addressed is: if an off-road vehicle travels over roads of different roughness at a specified speed, is there a significant difference in the optimal suspension settings pertaining to the different road conditions? From this investigation it is endeavoured to determine a speed and profile that can be used for further ride comfort optimisation in a model with more variables describing the suspension characteristics and also incorporating handling.

The three-dimensional vehicle model entails non-linear suspension characteristics. The standard vehicle suspension characteristics are used as baseline. The front and rear suspension characteristics are scaled with respect to the standard suspension by means of front damper and spring scaling factors and rear damper and spring scaling factors. For optimisation purposes the gradient-based Dynamic-Q algorithm, which has previously been used in conjunction with suspension optimisation [5] and [6] is used. There are four variables that can be adjusted: the rear and front spring scaling factors and the rear and front damper scaling factors.

In designing the hardware for a semi-active suspension, it is necessary to determine the optimal suspension settings that will best address ride comfort for roads varying from level and straight travelled at high speeds, to off-road conditions with severe unevenness and curvatures travelled at low speeds. Focussing on ride-comfort only, it is endeavoured to obtain the best settings that would improve the overall ride comfort. The question of 
optimised suspension settings for semi-active systems has been investigated from various angles by researchers. Gobbi et al. [7] used a simple two degree of freedom linear model to investigate the dynamic behaviour of passively and actively suspended vehicles running on randomly defined roads. Stochastic multi-objective optimisation is applied with the standard deviation of the vertical body acceleration to evaluate ride comfort, the standard deviation of the relative displacement between the wheel and vehicle body to evaluate working space and the standard deviation of the tyre radial force to evaluate road holding. The damping and stiffness is optimised for the active suspension case. The results indicate a trade-off between robustness and maximum mean performance. In his doctoral thesis Eriksson [8] indicated that for a bus subject to simulated road irregularities, the stiffness and damping associated with the rear axle suspension has a great influence on the discomfort within the bus. Elbeheiry and Karnopp [9] considered broadband stochastic roadway inputs, described in terms of a simplified displacement spectral density (PSD) at several intensity levels, to a quarter car model. The best possible isolation is sought subject to the constraint that the root mean square (RMS) suspension deflection remains constant. Fully active, limited active, optimal passive, actively damped and variable damper systems are considered and road input velocity is indicated to be white noise related. A policy for adapting suspension systems based on suspension travel is suggested. The idea proved to be suitable for road input resulting in large travel. Yoon and Hac [10] consider optimised control of semi active suspensions of a two degree of freedom (DOF) vehicle model for various road and speed conditions. Ground velocity input is modelled as white noise and the covariance thereof is described in terms of a road roughness parameter. The response of the system (body acceleration and tyre deflection) crossing two large bumps and an asphalt road at $20 \mathrm{~m} / \mathrm{s}$ is given for suspensions with and without adaptive capability based on preview. Marzaband et al. [11] consider paved roads with roughness presented by an elevation spectral density and surface irregularity standard deviation of $0.01 \mathrm{~m}$. A four-DOF half-car model is used to optimise suspension settings for ride comfort based on preview information. Tamboli and Joshi [12] determine values for the spring stiffness and damping coefficients when optimising for the mean square vertical acceleration of a vehicle travelling at different speeds over sinusoidal, highway and city type roads. A two-DOF model for half a car is 
used in the investigation. They point out that since the displacement spectral density (PSD) of the road input follows an exponentially decreasing curve it cannot be considered as white noise. Actual road information and a curve fitted PSD of the road are used as input. They find that for a heavy-duty truck with a wheelbase of $5.2 \mathrm{~m}$, the root mean square acceleration response (RMSAR) increases with increasing speed and decreases as the wheelbase increases. Considerable reduction in RMSAR is obtained when the suspension coefficients are optimised for RMSAR on highway type road conditions. Lozia [13] analyses vehicle behaviour (lateral displacement and acceleration, yaw velocity and heading angle) for a full vehicle model during a lane change at $80 \mathrm{~km} / \mathrm{h}$ on an even road, an average class D road and a poor road of class E [14] as obtained from a fast Fourier transform (FFT) of the PSD. He finds that road unevenness decreases lateral displacement by up to $23 \%$ of the lane width.

Gobbi et al. [15] optimised the vehicle suspension parameters for an artificial neural network-based vehicle model derived from a validated full vehicle model of a Fiat passenger car. The simulated vehicle passes over a randomly uneven road at $60 \mathrm{~km} / \mathrm{h}$, a non-symmetrical pothole at 40,80 and $120 \mathrm{~km} / \mathrm{h}$, a symmetrical pothole at 40 and $80 \mathrm{~km} / \mathrm{h}$ and a cleat at 30 and $50 \mathrm{~km} / \mathrm{h}$. Using multi-criteria optimisation, considerable improvement in comfort and road holding indices is obtained on a uneven road traversed at $60 \mathrm{~km} / \mathrm{h}$.

Ookubo et al. [16] develop and experimentally verify the yaw velocity, normalized with respect to the vehicle velocity, to steering angle ratio as a performance measure of handling on a rough road created from a road PSD. According to him this measure can be used to improve handling capability. For a quarter car linear model, Gobbi and Mastinu [17] derive the transfer functions for the standard deviation of vertical body acceleration, vertical force between tyre and road and relative displacement between wheel and body due to road input described by two different PSD formulations. Analytical expressions for the best trade-off for conflicting performance indices were obtained for the simplified PSD and thus the optimal suspension damping, suspension stiffness and tyre stiffness. In this case the optimal settings do not depend on speed. For the more complex description of the PSD method, the optimal settings are speed dependent, the suspension stiffness and damping have to be within derived boundaries and the tyre stiffness at its minimum 
value. Gobbi et al. [18] also optimised vehicle parameters for a full car handling model and a full car comfort model for different driving situations such as a J-turn, lane change, even/rough road, dry/wet roads and speeds from 0 to $50 \mathrm{~m} / \mathrm{s}$. Best comfort was obtained by reducing stiffness and damping at the front, damping at the rear and lower tyre pressures rear and front relative to production car values. For improved handling performance the rear roll stiffness was increased and toe-out angles were set at the front. Slight camber angles were also introduced.

Optimisation has also been accomplished by multi-criteria optimisation using genetic algorithms and considering the different driving conditions to determine the passive suspension and chassis settings [15]. Shieh et al. [19] investigated the optimal design for a passive suspension of a light rail vehicle over an irregular track with a gradient of $1 \%$ travelling at $19.4 \mathrm{~m} / \mathrm{s}$. Nine suspension variables modelled in a pitch plane model were optimised with constraints on the suspension travel and the objective function related to the overall vertical acceleration. Convergence was obtained with a multi-objective evolutionary search approach, but not by application of a genetic algorithm. Deprez et al. [20] modelled a hydro-pneumatic element that can serve as part of a cabin suspension and used the global optimizer DIRECT to optimize the vibration dose value (VDV) and frequency response function for three measured terrains. The terrains were described as a field, paved road and unpaved road. The results indicated that when the suspension was optimised in terms of VDV for one type of road input, the VDV was still acceptable for the other roads inputs.

\section{Deciding on the best objective function}

In the study presented here, optimisation of suspension settings is performed with the gradient-based Dynamic-Q algorithm [21]. Dynamic-Q is particularly well suited to practical engineering optimisation problems, where noise may be present in the evaluation of the objective and constraint functions via computational simulations. It has also successfully been applied to optimisation of suspension settings for ride comfort and handling [5] and [6]. In previous work the ride comfort function being optimised was either the root mean square (RMS) value of the simulated vertical acceleration at the left rear passenger seat over the time period frequency, weighted in terms of the British 
Standard 6841 filter [5], or the RMS vertical acceleration value calculated as mentioned, but for the combined driver plus the left rear passenger seat [6]. The question arose as to which objective function was the most suitable in order to obtain the best ride comfort for both the passenger and driver. Table 1 summarises the results for a simulation of a vehicle travelling over a measured road profile at a speed of $60 \mathrm{~km} / \mathrm{h}$. The lowest RMS vertical acceleration values for the passenger are obtained when optimisation is performed with the combined RMS of the driver and passenger as optimisation objective. When optimising for the driver RMS vertical acceleration, a lower RMS vertical acceleration value for the driver is obtained, but the passenger RMS vertical acceleration is $14 \%$ higher than that obtained when optimising for the combined RMS vertical acceleration. Consequently, this approach could result in unacceptable high values of passenger RMS vertical acceleration if not kept in check. The driver RMS vertical acceleration is $13 \%$ higher when optimising for combined RMS vertical acceleration than when optimising for the driver RMS vertical acceleration. In view of both passenger and driver RMS vertical acceleration the combined RMS vertical acceleration is chosen for optimisation of suspension settings with respect to ride comfort. Future reference to RMS vertical acceleration will thus incorporate combined passenger and driver values unless otherwise stated. 
Table 1.

Comparison of results when using different objective functions

\begin{tabular}{|l|l|l|l|l|l|}
\hline \multicolumn{3}{|c|}{} & \multicolumn{3}{|l|}{ Parameter results obtained for different objective functions } \\
\hline & $\begin{array}{l}\text { Driver } \\
\text { RMS }\end{array}$ & $\begin{array}{l}\text { Passenger } \\
\text { RMS }\end{array}$ & $\begin{array}{l}\text { (Driver + passenger) } \\
\text { RMS/2 }\end{array}$ & $\begin{array}{l}\text { Objective } \\
\text { function } \\
\text { value }\end{array}$ & $\begin{array}{l}\text { (Driver + passenger) } \\
\text { RMS }\end{array}$ \\
\hline $\begin{array}{l}\text { Objective function used } \\
\text { (D)iver + passenger) }\end{array}$ & 3.13 & 3.39 & 3.26 & 6.52 & 6.52 \\
\hline RMS & 2.78 & 3.88 & 3.33 & 2.78 & 6.66 \\
\hline Priver RMS & 3.38 & 3.58 & 3.48 & 3.58 & 6.96 \\
\hline
\end{tabular}

\section{Measured results}

A Land Rover Defender 110 (1992 model) with standard suspension was used as test vehicle for validating simulation results. Tests were performed over $100 \mathrm{~m}$ Belgian paving at the Gerotek vehicle test facility [22] at different speeds. The BS weighted RMS vertical acceleration value [2] at the left rear seat and left front seat as well as the combined value is shown in Fig. 1. Likely, subjective reactions to frequency weighted RMS are listed in Table 2 [2]. A comparison of Fig. 1 and Table 2 indicates the harshness of the ride likely to be experienced by the occupants at different speeds due to the road input. The duration of the vertical acceleration measurement, the associated average speed and related RMS vertical acceleration of the left front bumper point added to that of the passenger seat, is indicated in Table 3. The trends observed with ride comfort decreasing with increasing speed, is the same as the results observed by Newell and Murphy [23]. The frequency content of the road is depicted in Fig. 2, while Fig. 3 shows the frequency content experienced at the two measuring positions. 


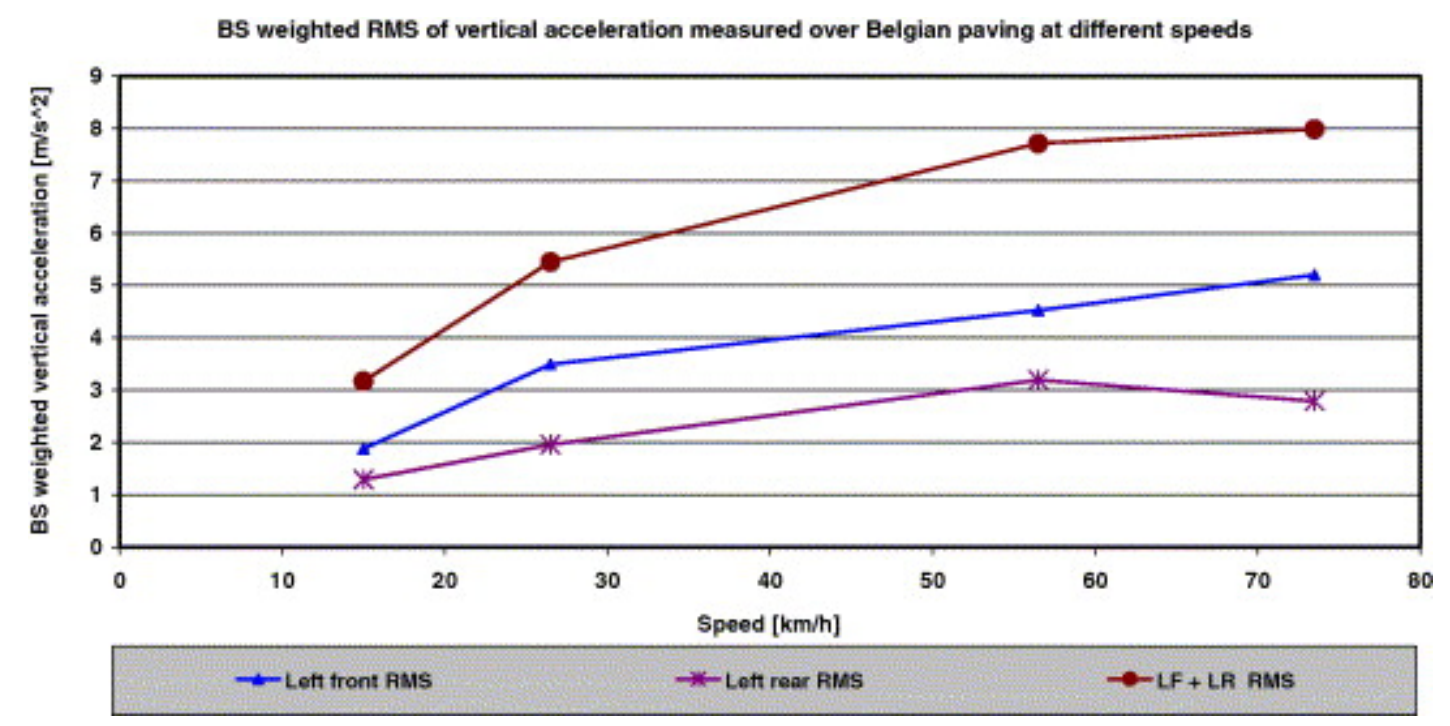

Fig. 1. Measured effect of speed on ride comfort for standard vehicle on Belgian paving. Table 2.

Levels of acceptability of ride quality

\begin{tabular}{|l|l|}
\hline Range: BS weighted RMS of Vertical acceleration $\mathbf{( m / \mathbf { s } ^ { \mathbf { 2 } } )}$ & Acceptability \\
\hline$<0.315$ & Not uncomfortable \\
\hline $0.315-0.63$ & A little uncomfortable \\
\hline $0.5-1$ & Fairly uncomfortable \\
\hline $0.8-1.6$ & Uncomfortable \\
\hline $1.25-2.5$ & Very uncomfortable \\
\hline$>2$ & Extremely uncomfortable \\
\hline
\end{tabular}


Table 3.

Ride comfort over Belgian paving measured at different velocities

\begin{tabular}{|l|l|l|l|}
\hline $\begin{array}{l}\text { Speed } \\
\mathbf{( k m} / \mathbf{h})\end{array}$ & $\begin{array}{l}\text { Speed } \\
\mathbf{( m / s )}\end{array}$ & $\begin{array}{l}\text { Duration } \\
\mathbf{( s )}\end{array}$ & $\begin{array}{l}\text { Left front plus passenger BS weighted RMS } \\
\left.\text { Vertical acceleration } \mathbf{( m} / \mathbf{s}^{\mathbf{2}}\right)\end{array}$ \\
\hline 15 & 4.2 & 23.6 & 3.1674 \\
\hline 26.5 & 7.4 & 14.25 & 5.4463 \\
\hline 56.5 & 15.7 & 7 & 7.7147 \\
\hline 73.5 & 20.4 & 5.3 & 7.9864 \\
\hline
\end{tabular}

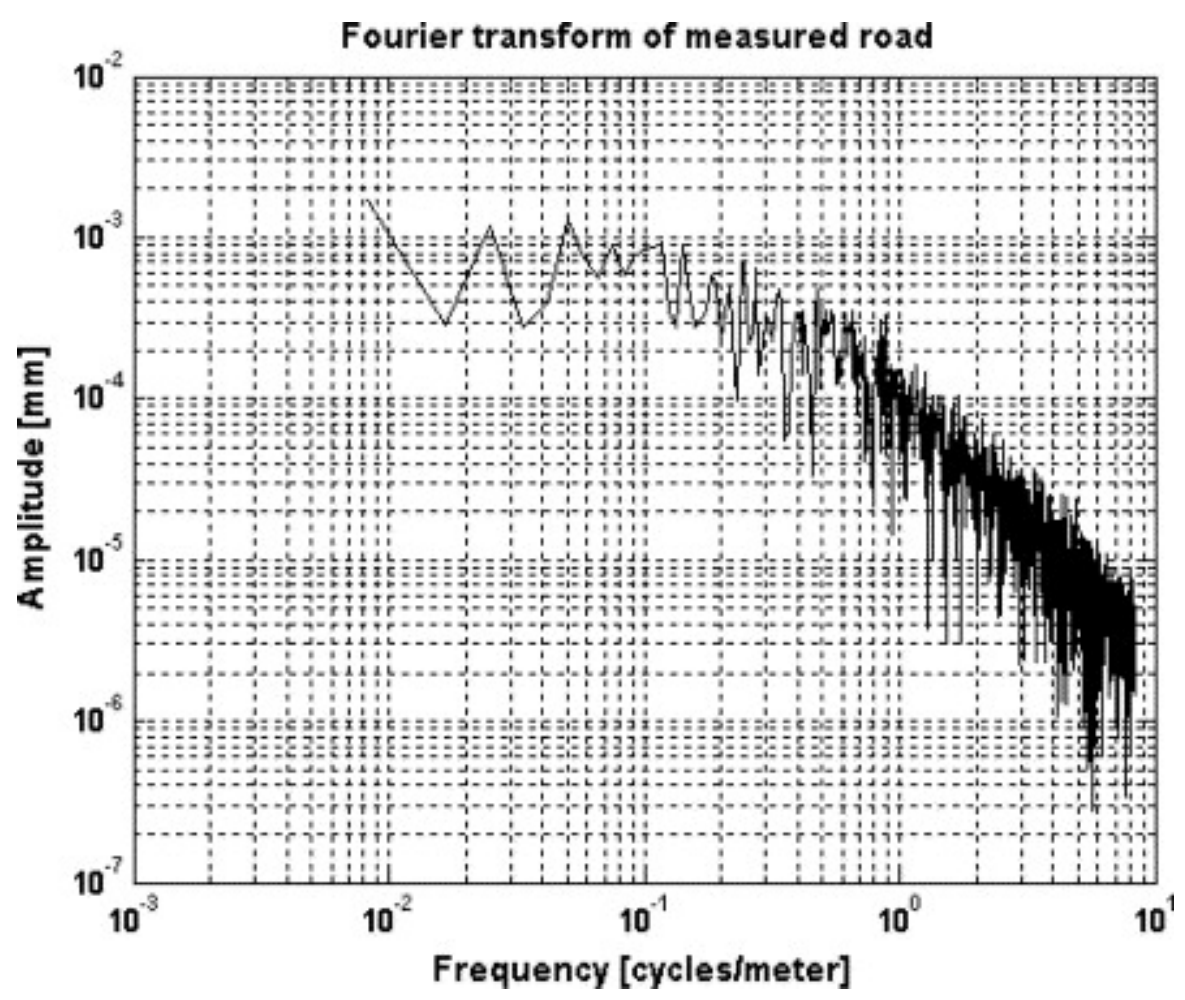

Fig. 2. Frequency content of measured road. 


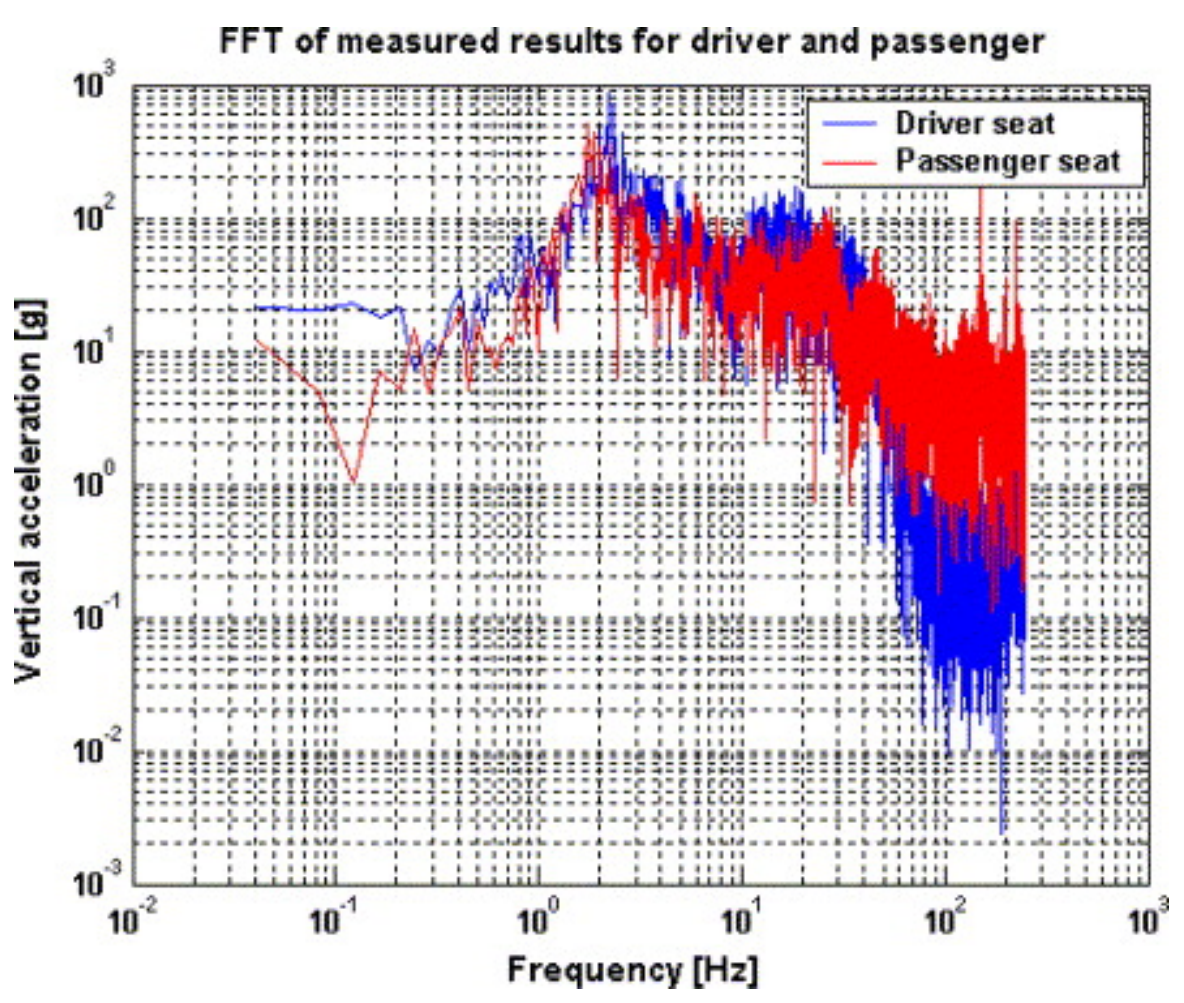

Fig. 3. Frequency content of measured accelerations.

\section{Road profiles}

As road profiles are characterised in terms of displacement power spectral densities according to the ISO 8608 standard [14], different roads were created in MATLAB software using the characterising road indexes as indicated in Table 4 [24]. The displacement power spectral density of a road profile is described by the following equation:

$$
S_{Z}=A \phi^{-n}
$$

where $S_{z}$ is the vertical displacement spectral density (mean vertical

displacement $)^{2} /($ frequency band), $n$ is the road index, $A$ is the roughness coefficient and $\phi$ is the spatial frequency measured in cycles/meter $(\mathrm{c} / \mathrm{m})$. Spatial frequencies ranged from 0.05 to $10 \mathrm{c} / \mathrm{m}$, (wavelength from 0.1 to $20 \mathrm{~m}$ ), and the frequency interval was $3.05 \times 10^{-4} \mathrm{c} / \mathrm{m}$. The measured Belgian paving (2009 points over $100 \mathrm{~m}$ ) has also been used as road input. Table 4 [24] lists the values of the road indexes and RMS vertical 
displacement values related to the different roads used in this investigation. Two tracks for the left and right wheels, were created from the PSDs by using a randomly created phase angle for each frequency point. The profile displacement PSDs are shown in Fig. 4 with the darker shade referring to the driver.

Table 4 .

Descriptive parameters of road profiles [24]

\begin{tabular}{|l|l|l|l|l|}
\hline Description & $\begin{array}{l}\text { Road index, } \\
\text { A }\end{array}$ & $\begin{array}{l}\text { Roughness } \\
\text { coefficient, } \boldsymbol{n}\end{array}$ & $\begin{array}{l}\text { Road RMS value } \\
\mathbf{( m )}\end{array}$ & $\begin{array}{l}\text { Spatial } \\
\text { frequency } \\
\text { range (m } \mathbf{m}^{-\mathbf{1}}\end{array}$ \\
\hline Belgian paving measured & $7.8 \mathrm{e}-5$ & 4.85 & 0.006 & $0.01-1$ \\
\hline Gravel highway & $4.4 \mathrm{e}-6$ & 2.1 & $0.0003-0.0006$ & $0.05-10$ \\
\hline Pasture & $3.0 \mathrm{e}-4$ & 1.6 & $0.008-0.014$ & $0.05-10$ \\
\hline Ploughed land & $6.5 \mathrm{e}-4$ & 1.6 & $0.015-0.02$ & $0.05-10$ \\
\hline Random test course & $3.16 \mathrm{e}-4$ & 2.27 & $0.007-0.02$ & $0.05-10$ \\
\hline
\end{tabular}

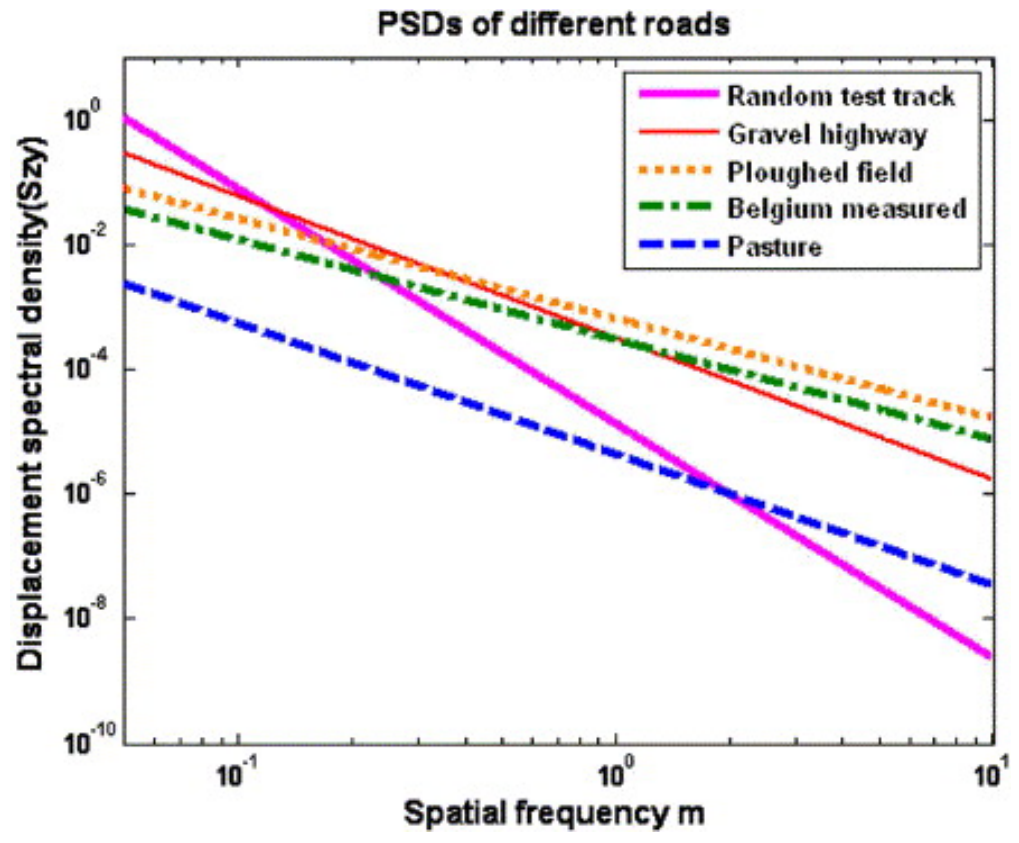

Fig. 4. Displacement spectral density of the different roads. 


\section{Determining optimal suspension settings}

Several questions have to be addressed when determining the optimal suspension settings. The first is to what extent does the optimal suspension settings vary if a road of given roughness is traversed at different speeds. Secondly, what levels of ride comfort can be achieved in these cases? Another question at hand is if an off-road vehicle travels over roads of different roughness with a suspension setting optimised for one road at a specified speed, what is the effect on ride comfort? Furthermore, what is the effect if an off-road vehicle travels at a specified speed over a particular road profile with the suspension setting optimised for a different speed? Also how much will the ride comfort be affected and how much can the suspension settings vary so that the ride comfort is still within $5 \%$ of the optimal suspension value?

\subsection{The simulation model}

In order to address these issues and to be able to apply optimisation algorithms, a full vehicle model of a Land Rover Defender 110 was created in the multibody dynamics software package MSC.ADAMS, version 12. The model consists of 16 unconstrained DOF, 23 moving parts, 11 spherical joints, 10 revolute joints and 9 Hookes joints. A variable torque dependent on the difference between the instantaneous and the desired speed drives the wheels. For the tyres the MSC.ADAMS 521 interpolation tyre model is used [6]. The model has been validated against test results for vertical dynamics with the vehicle equipped with the standard suspension and driving at several speeds over local Aberdeen Proving Grounds (APG) $100 \mathrm{~mm}$ bumps. The results for $25 \mathrm{~km} / \mathrm{h}$ are shown in

Fig. 5. Correlation between measured and simulated results is very good, especially with respect to vertical acceleration that is used as a measure of ride comfort. 

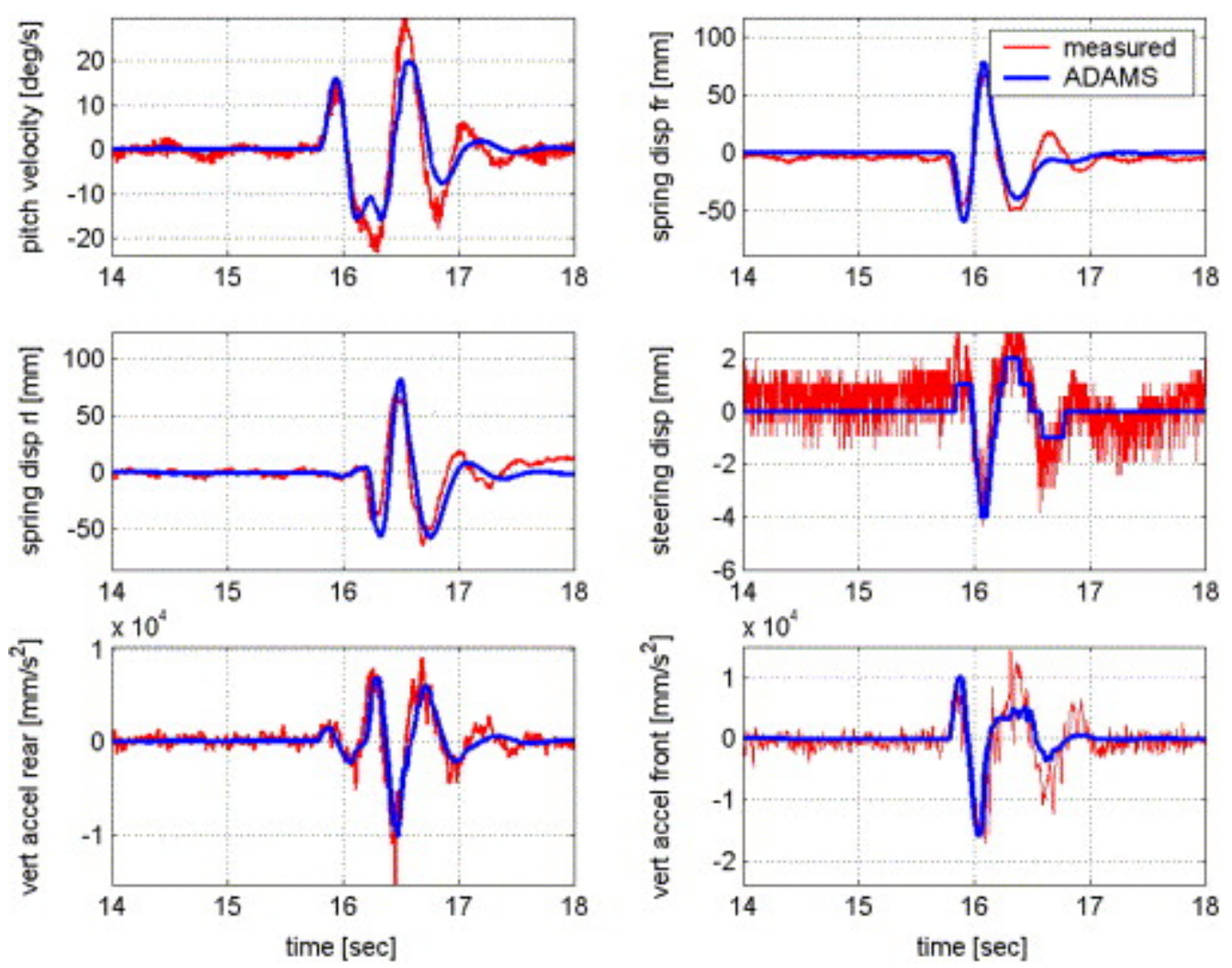

Fig. 5. Model validation results for passing over $100 \mathrm{~mm}$ APG bumps at $25 \mathrm{~km} / \mathrm{h}$.

\subsection{The optimisation procedure}

For optimisation purposes a mathematical model of the four stage semi-active spring damper system was introduced in the vehicle model. The system incorporates two gas accumulators and two damper packs fitted with bypass valves enabling two damper characteristics and two spring characteristics for every suspension unit. The front and rear gas volumes representing the spring stiffness, and front and rear damper settings, scaled with respect to the baseline setting, was used as variables. By adjusting the gas volume and scaling factor, the BS weighted RMS value of the combined driver and passenger RMS was minimized, using the Dynamic-Q algorithm. Due to physical restrictions, gas volumes may vary between 0.006 and 0.6 litre and the damping coefficient scaling factor between 0.03 and 3. Speed varies from 10 to $100 \mathrm{~km} / \mathrm{h}$ and simulation time is adjusted between 8 and $12 \mathrm{~s}$ to compensate for the time required to travel over the profiles created at lower speed. 


\section{Results}

\subsection{Optimal suspension settings for different roads and speeds}

The combined RMS vertical acceleration for optimised suspension settings at different speeds and for the various roads is shown in Fig. 6. The information pertaining to the test results of the standard vehicle is also included for the purpose of comparison (unconnected points). For the optimised suspension, the ride comfort over the Belgian paving is improved, particularly at lower speeds. Also the trend of decreasing comfort (larger RMS vertical acceleration) with increasing speed, is the same for optimised suspensions as that observed from the measured results. These results are indicated in Fig. 7 and Fig. 8 for the driver and rear passenger, respectively. At higher speeds than those for which values have been indicated, the model no longer gives valid results due to severe wheel hop that results in instabilities in the current model.

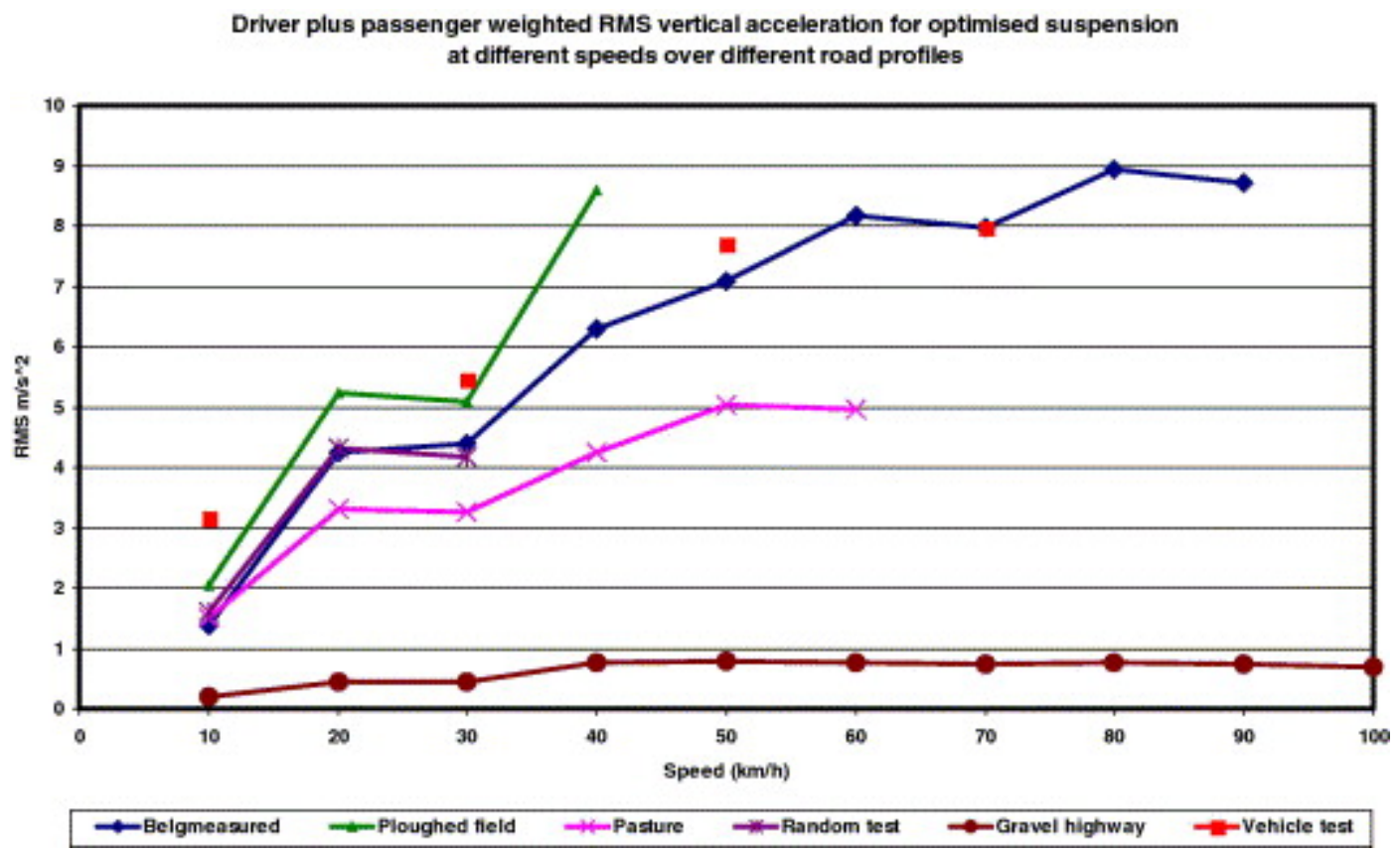

Fig. 6. Passenger plus driver BS weighted RMS vertical acceleration for optimised suspension settings at different speeds over various roads. 


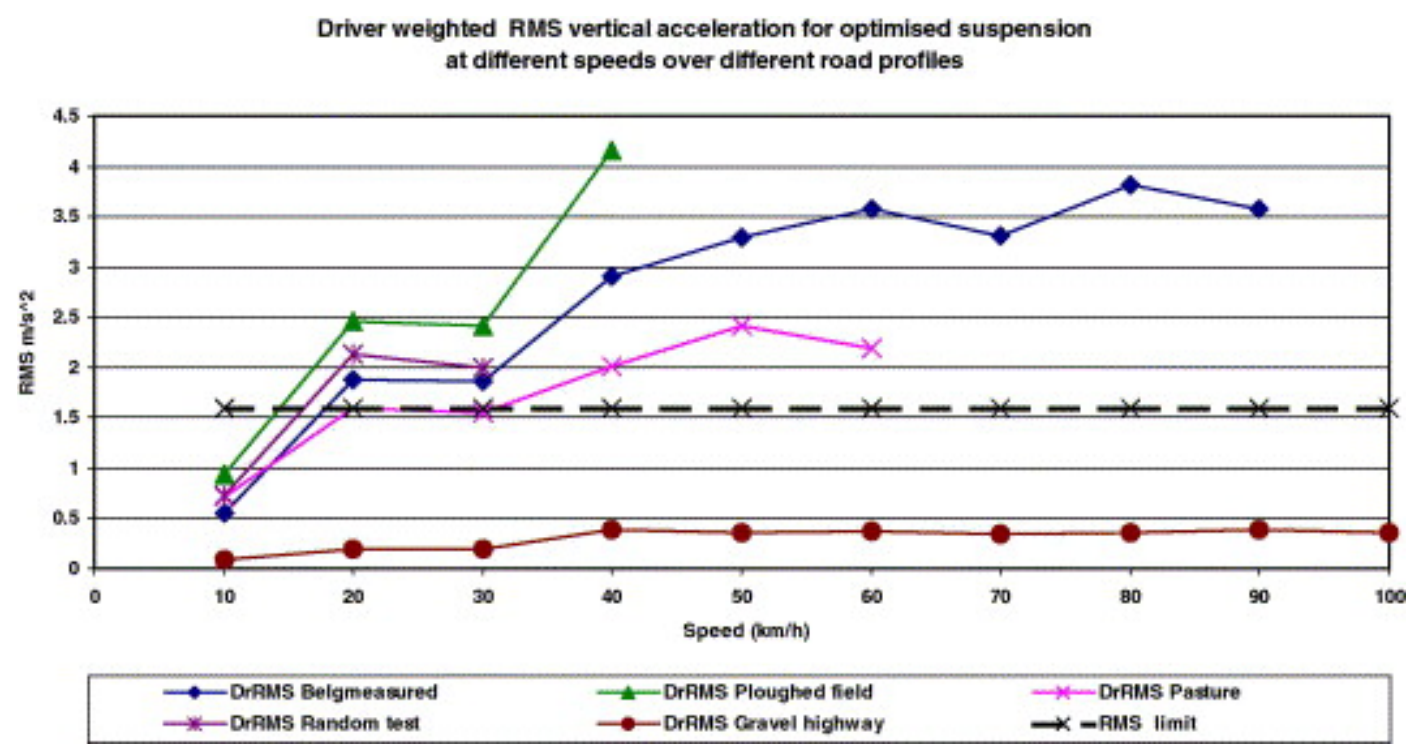

Fig. 7. Driver BS weighted RMS vertical acceleration for optimised suspension settings at different speeds over various roads.

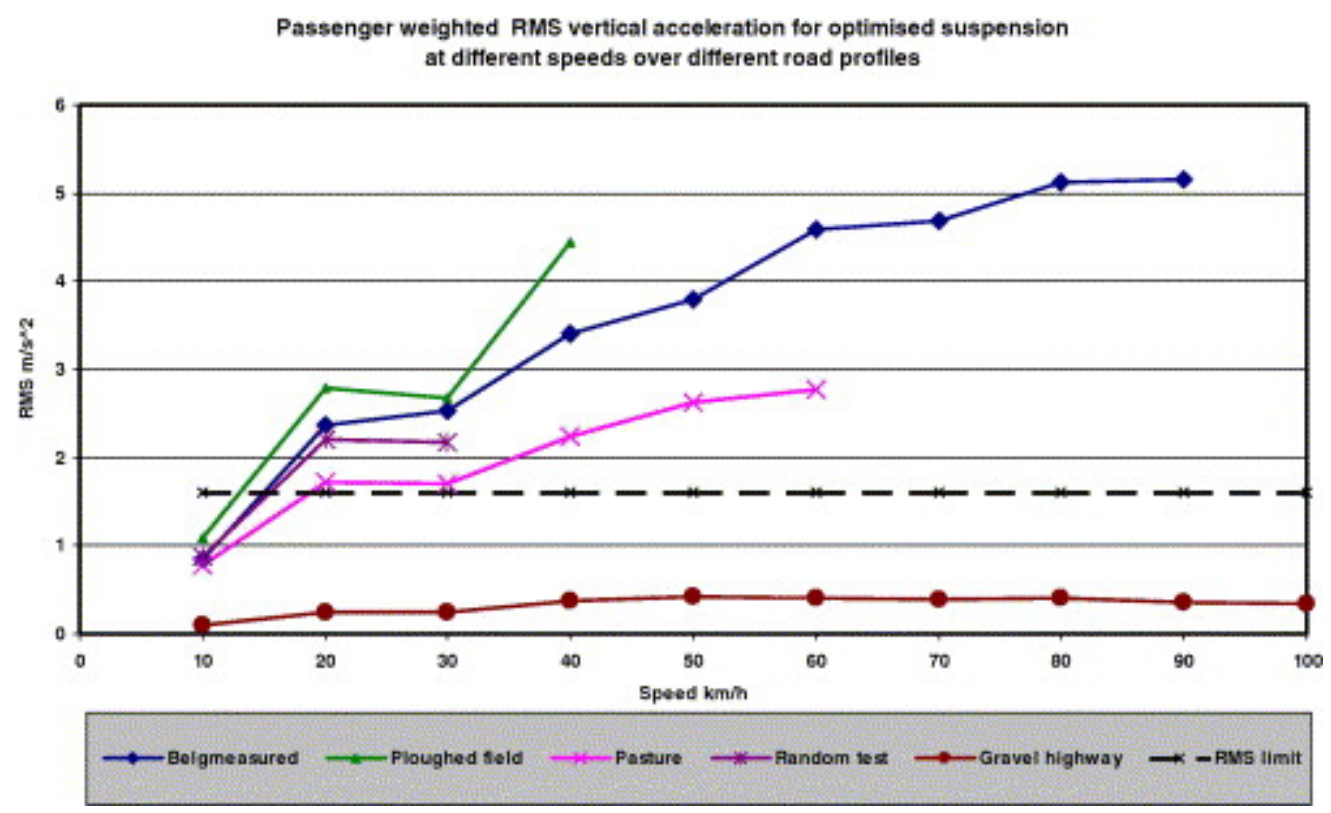

Fig. 8. Rear passenger BS weighted RMS vertical acceleration for optimised suspension settings at different speeds and the various roads.

In Fig. 7 and Fig. 8, the limiting acceptable value of ride comfort of $1.6 \mathrm{~m} / \mathrm{s}^{2}$ (see Table 2), has also been indicated. From these results, the limiting speeds can be derived at which the vehicle, with a suspension optimised for combined driver plus passenger 
comfort, can traverse the different roads. The ride-limiting speeds are tabulated in Table 5.

Table 5 .

Ride-limiting speed pertaining to the left front and left rear seats for optimised speed and track suspension settings

\begin{tabular}{|c|c|c|c|c|}
\hline Terrain & $\begin{array}{l}\text { Road } \\
\text { index, } A\end{array}$ & $\begin{array}{l}\text { Roughness } \\
\text { Index, } n\end{array}$ & $\begin{array}{l}\text { Ride limiting } \\
\text { speed driver } \\
(\mathbf{k m} / \mathbf{h})\end{array}$ & $\begin{array}{l}\text { Ride limiting } \\
\text { speed left rear } \\
(\mathrm{km} / \mathrm{h})\end{array}$ \\
\hline BelgMeasured & $7.8 e^{-5}$ & 4.85 & 18 & 15 \\
\hline Gravel highway & $4.4 e^{-}-6$ & 2.1 & $>100$ & $>100$ \\
\hline Pasture & $3.0 e^{-4}$ & 1.6 & 32 & 18 \\
\hline Ploughed field & $6.5 e^{-4}$ & 1.6 & 14 & 15 \\
\hline $\begin{array}{l}\text { Random test } \\
\text { course }\end{array}$ & $3.16 e^{-4}$ & 2.27 & 14 & 13 \\
\hline
\end{tabular}

The suspension settings resulting from the optimisation at different speeds for the various roads are shown in Fig. 9, Fig. 10, Fig. 11 and Fig. 12.

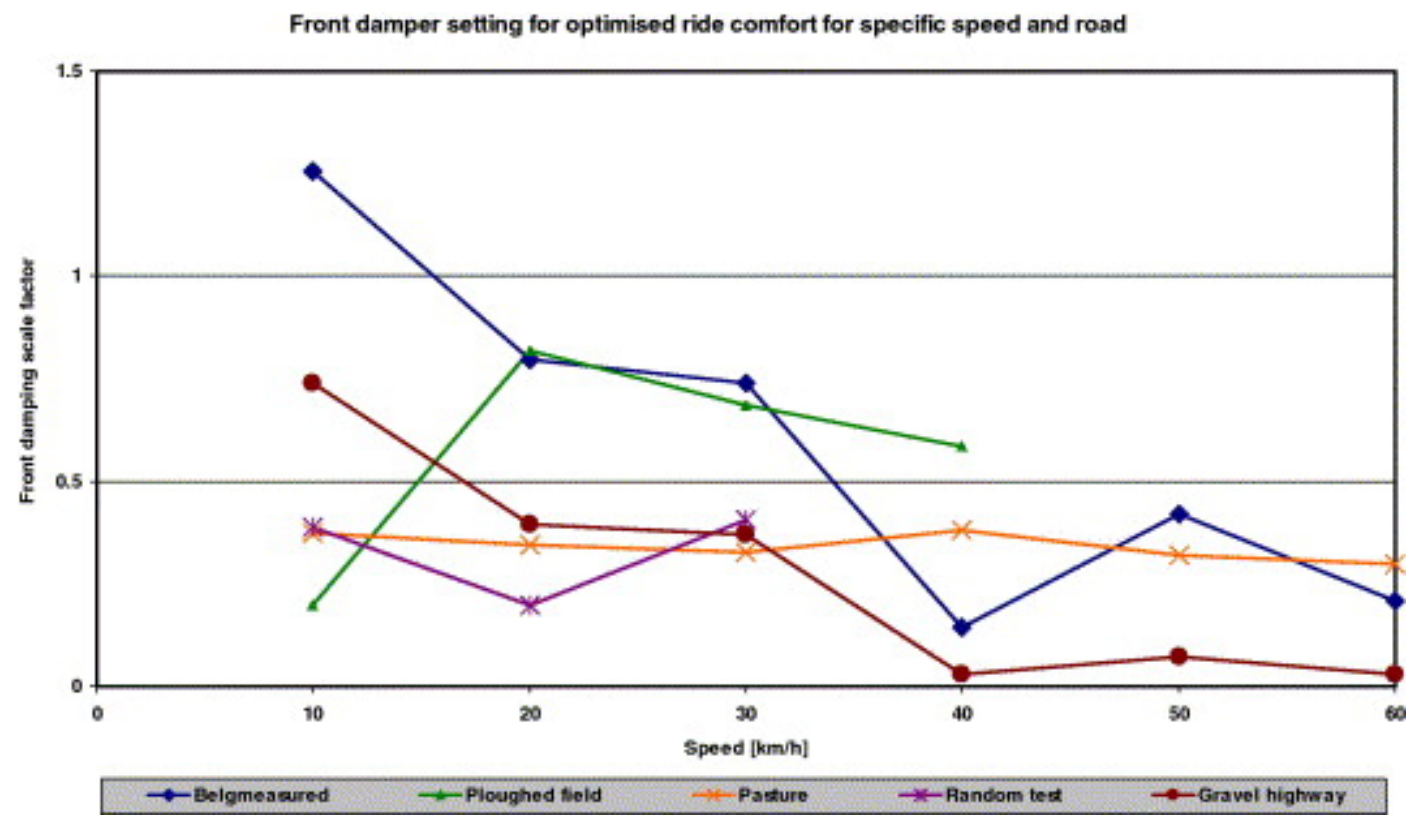


Fig. 9. Values of front damper settings for optimum driver plus passenger ride comfort.

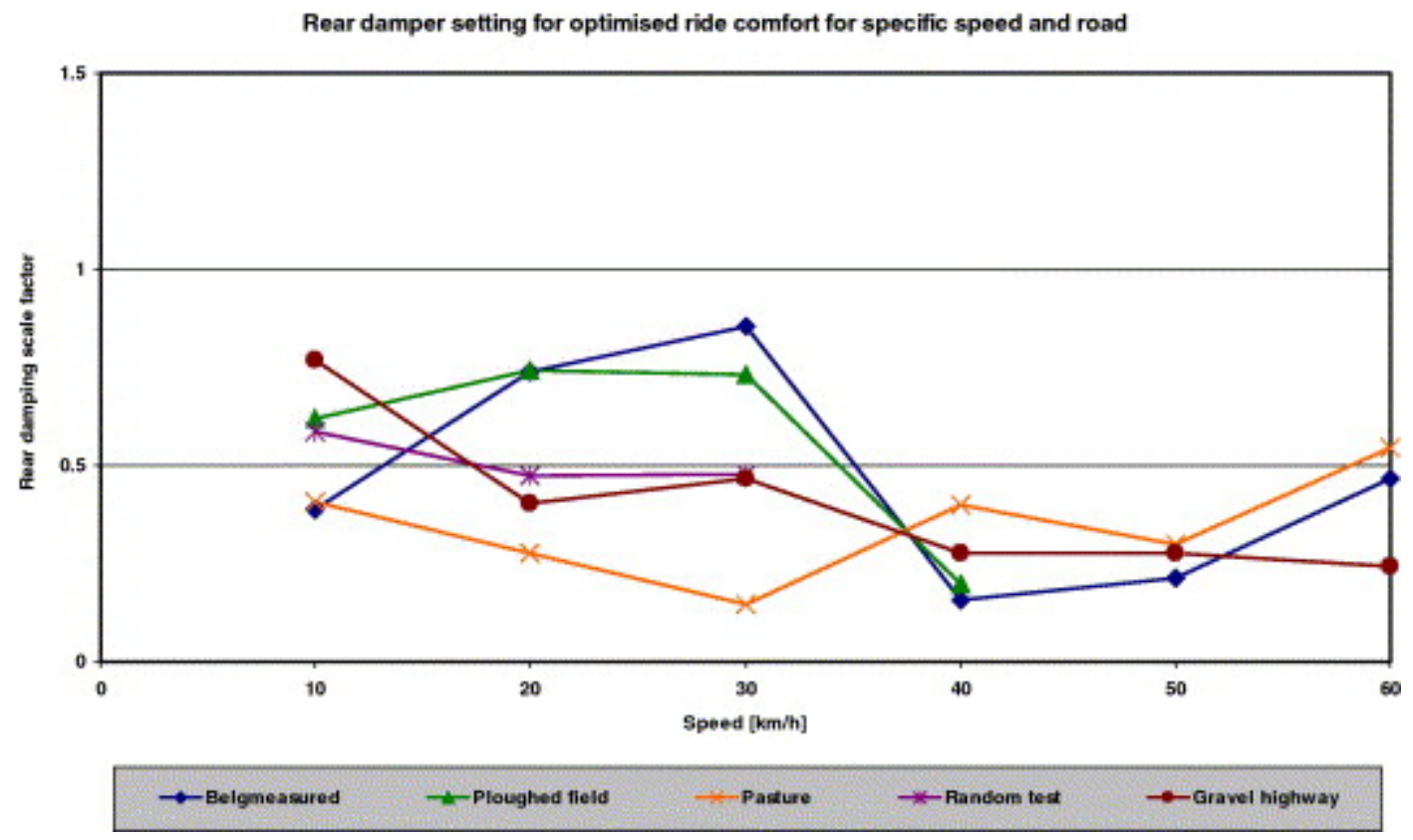

Fig. 10. Values of rear damper settings for optimum driver plus passenger ride comfort.

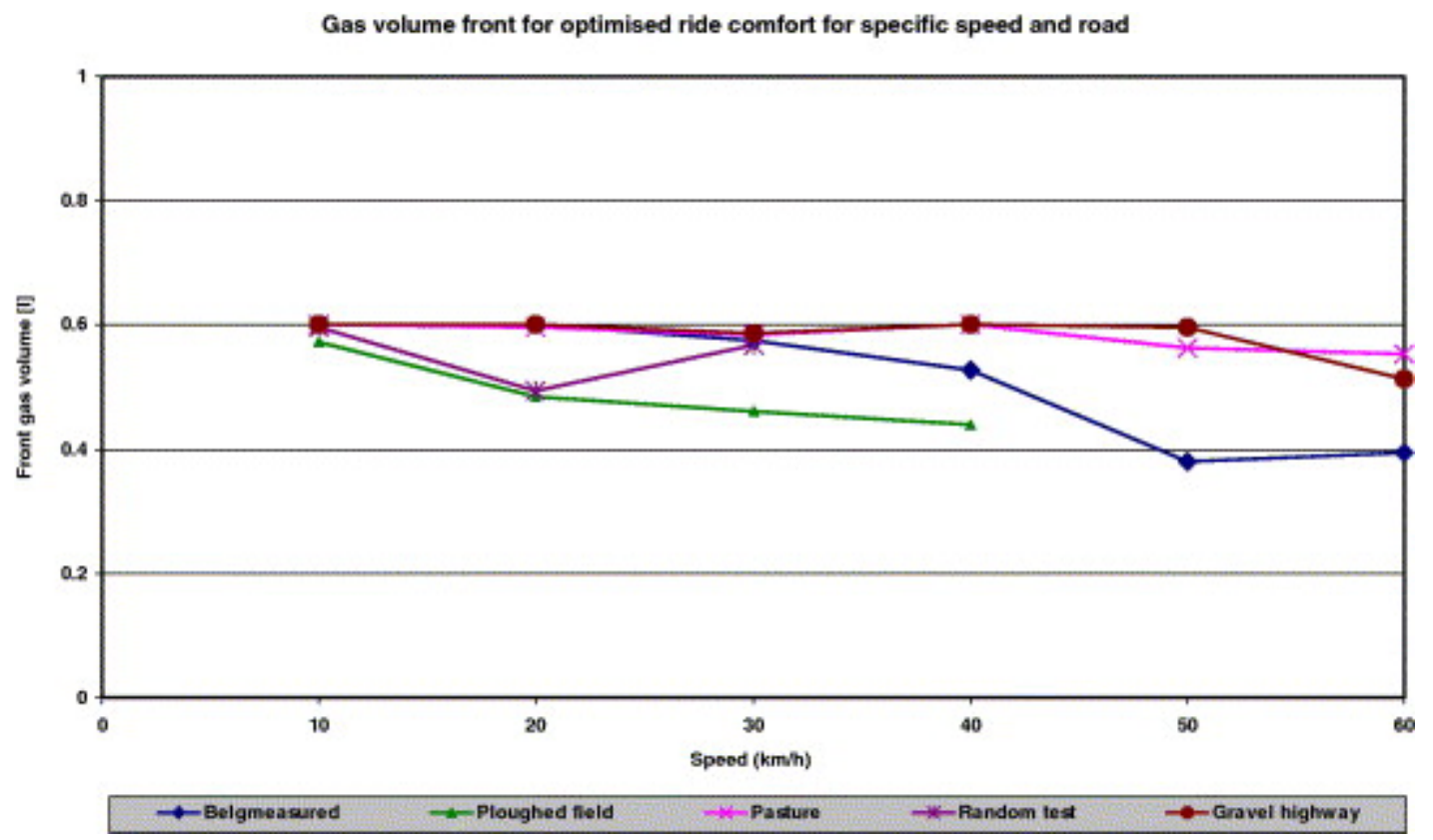

Fig. 11. Values of front gas volume settings for optimum driver plus passenger ride comfort. 


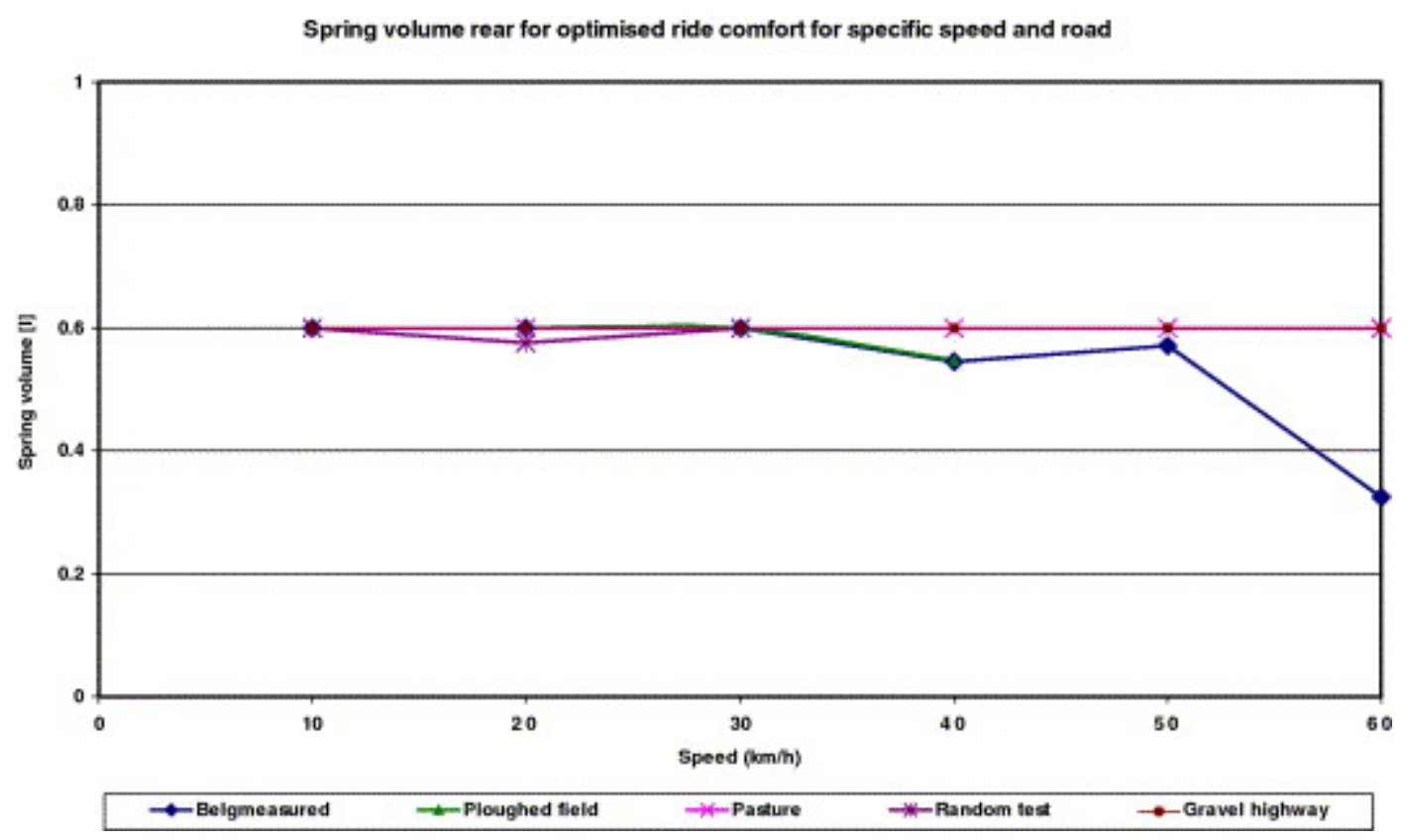

Fig. 12. Values of rear gas volume settings for optimum driver plus passenger ride comfort.

For velocities, where severe wheel movement has not occurred for the different roads, the optimal front damping coefficient scaling factors range from 0.03 to 1.3 and the rear from 0.2 to 0.8 , i.e. low damping force for all types of roads. For a particular road the variation with speed depends on the roughness of the road. The damper settings tend to pass through a minimum value at a speed depending on the road conditions and in general less damping is required as speed increases and more as the road roughness increases. The rear damping settings for the different roads are closer to one another than for the front dampers. No generalisation can be made concerning the rear as compared to the front damping. The gas volume at the front should be large, i.e. soft suspension, at low speeds and needs to decrease for higher speeds and increasing roughness of the road profile. A stiffer spring seems to be required at the front compared to the rear. A trend towards an increasing stiffness (smaller gas volumes) is observable with increasing velocity and road roughness as can be expected as less body movement but more wheel movement needs increased suspension travel to prevent hitting bump and rebound stops. 


\subsection{Using optimisation results for one road at a particular speed}

The next part of the investigation concerned the ride comfort that could be achieved if the optimised suspension setting obtained for one road at a particular speed is used for different roads at different speeds. Fig. 13, Fig. 14 and Fig. 15 show combined comfort for the measured Belgian paving, gravel highway and pasture, respectively, at speeds of $10 \mathrm{~km} / \mathrm{h}, 20 \mathrm{~km} / \mathrm{h}$ and $30 \mathrm{~km} / \mathrm{h}$ when the suspension setting is at the optimal value for the Belgian paving at $50 \mathrm{~km} / \mathrm{h}$. Similar results were obtained for the other roads. These results are compared to the results for the baseline setting and the optimum setting. From the results it is apparent that ride comfort can be improved by optimising the suspension setting. Furthermore, for the speeds chosen the ride comfort of every road at every speed is considerably better than the ride comfort obtained for the baseline setting when the value of the optimum suspension setting derived for the measured track at $50 \mathrm{~km} / \mathrm{h}$ is used. The ride comfort obtained at this setting is also comparable to the best ride comfort obtainable for the speed and terrain (depending on the speed and terrain). The improvement over the baseline suspension is also reflected when considering the ride limiting speed pertaining to the different suspension settings as listed in Table 6.

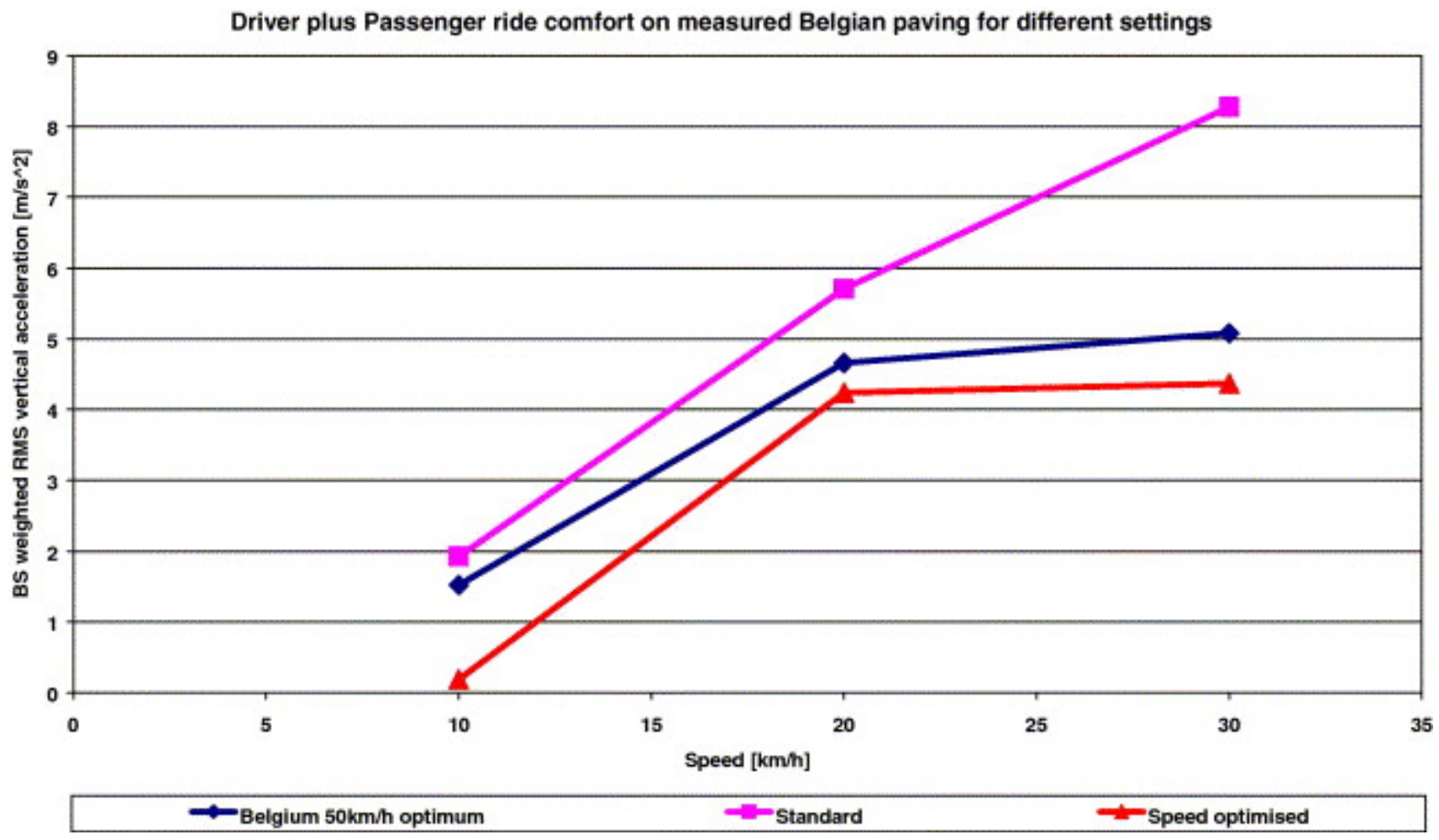


Fig. 13. Driver plus rear passenger seat ride comfort levels over Belgian paving with suspension setting at optimum, baseline and $50 \mathrm{~km} / \mathrm{h}$ measured Belgian paving optimum levels.

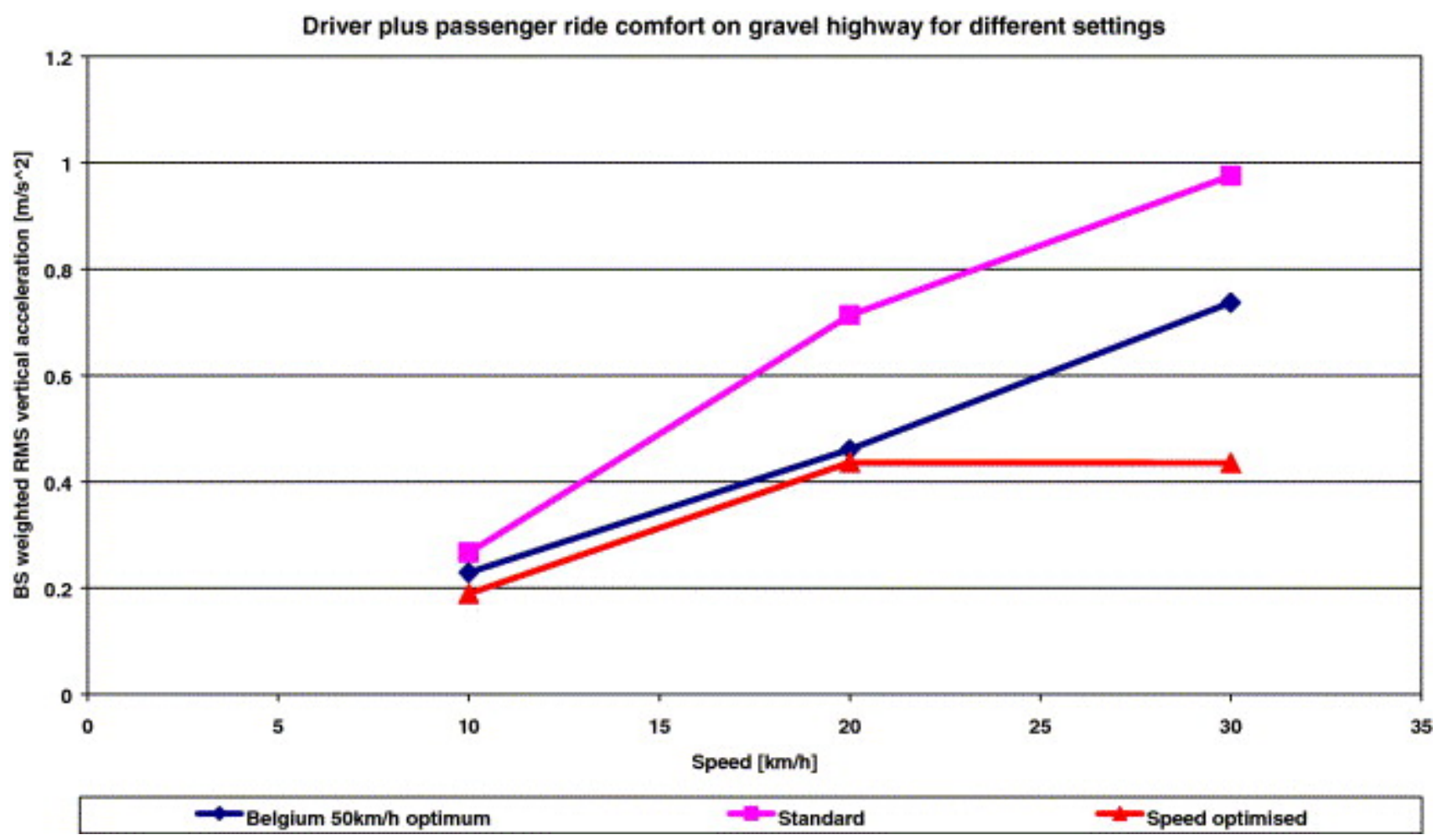

Fig. 14. Driver plus rear passenger seat ride comfort levels over gravel highway with suspension setting at optimum, baseline and $50 \mathrm{~km} / \mathrm{h}$ measured Belgian paving optimum levels. 


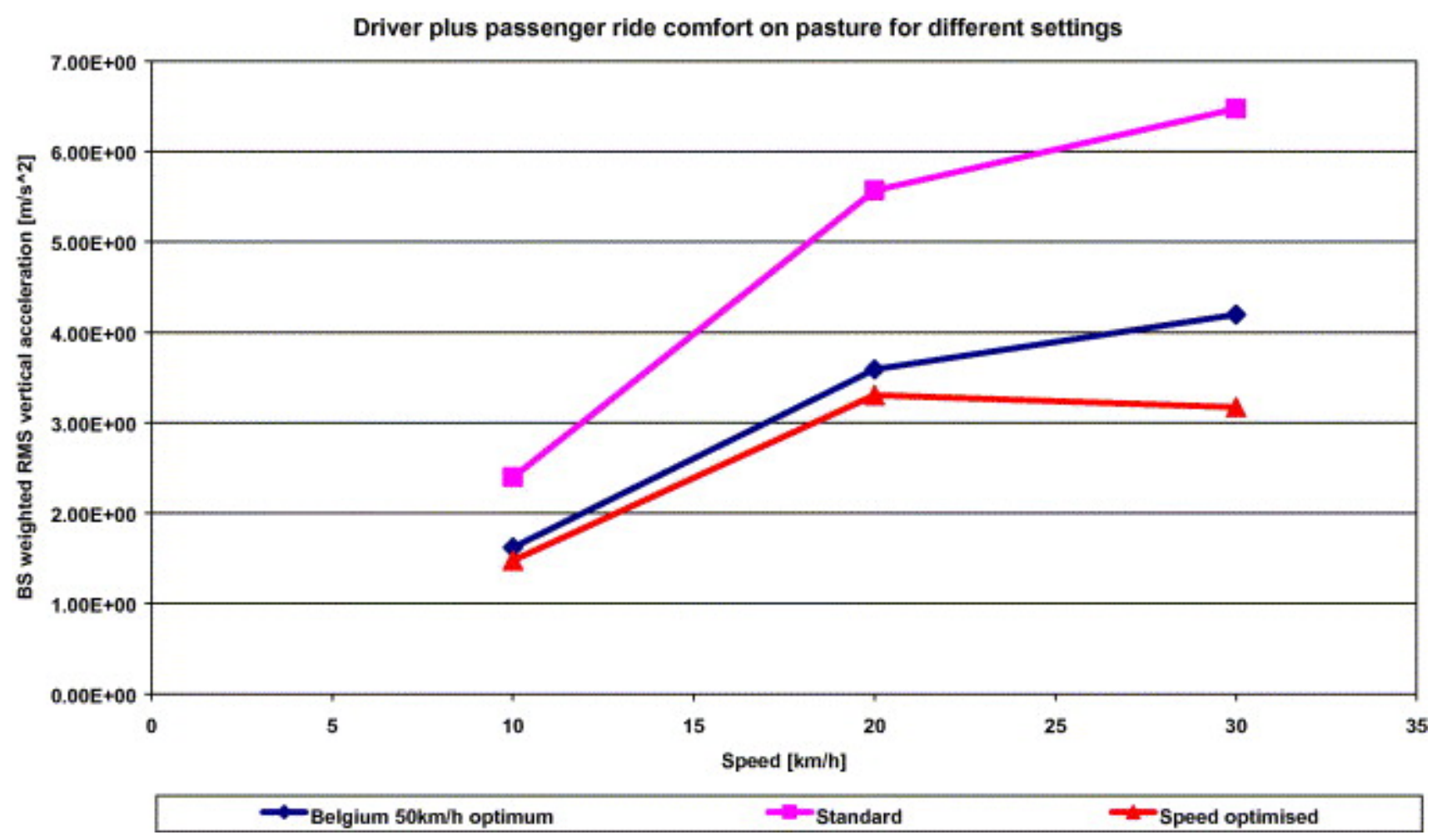

Fig. 15. Driver plus rear passenger seat ride comfort levels over pasture with suspension setting at optimum, baseline and $50 \mathrm{~km} / \mathrm{h}$ measured Belgian paving optimum levels.

Table 6.

Ride limiting speed on different tracks pertaining to different suspension settings

\begin{tabular}{|l|l|l|l|l|l|l|}
\hline Road & \multicolumn{2}{|l|}{$\begin{array}{l}\text { Baseline ride limiting } \\
\text { speed (km/h) }\end{array}$} & \multicolumn{2}{l|}{$\begin{array}{l}\text { \% Improvement using } \\
\text { Belgian 50 km/h } \\
\text { optimum }\end{array}$} & \multicolumn{2}{l|}{$\begin{array}{l}\text { \% Improvement } \\
\text { using optimisation } \\
\text { per speed }\end{array}$} \\
\hline & Driver & Passenger & Driver & Passenger & & \\
\hline $\begin{array}{l}\text { Belgian } \\
\text { measured }\end{array}$ & 14 & 12 & 16 & 19 & 29 & 38 \\
\hline $\begin{array}{l}\text { Ploughed } \\
\text { field }\end{array}$ & 10 & 10.3 & 25 & 17 & 40 & 26 \\
\hline Pasture & 12.7 & 12 & 36 & 50 & 57 & 50 \\
\hline $\begin{array}{l}\text { Random } \\
\text { test track }\end{array}$ & 12 & 11.3 & 29 & 37 & 35 & 37 \\
\hline
\end{tabular}




\subsection{Sensitivity of ride comfort to spring and damper adjustments}

In the final instance the sensitivity of ride comfort to suspension settings is considered.

The variation in the suspension settings, associated with a 5\% decrease in the ride comfort for the passenger and driver combined on the different terrains has been considered. Values for rear damping scale factors and rear spring volumes are shown for some roads and speeds from 20 to $60 \mathrm{~km} / \mathrm{h}$ in Fig. 16 and Fig. 17. Solid lines relate to minimum ride comfort values and dotted lines to $5 \%$ increase in discomfort values.

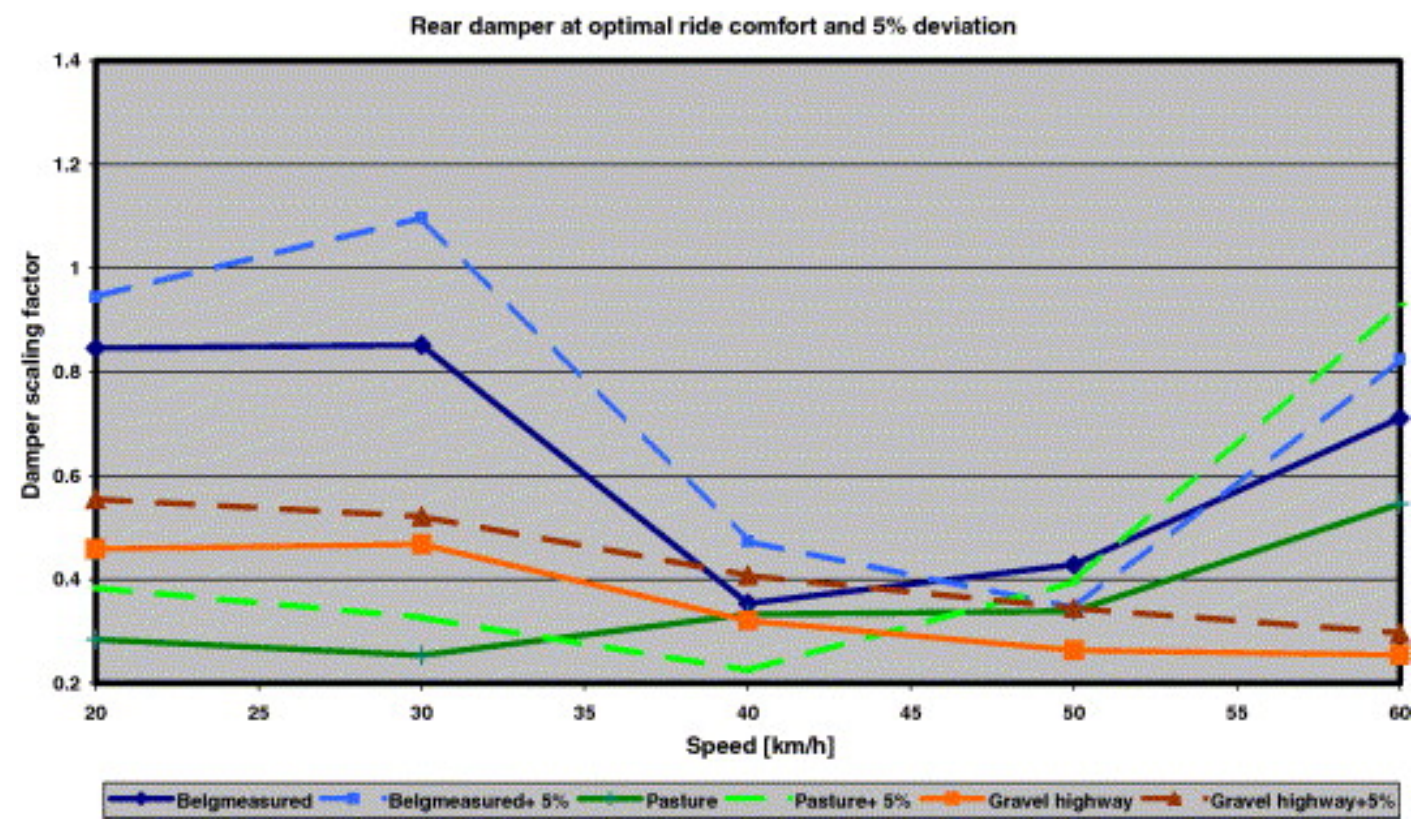

Fig. 16. Rear damper setting associated with optimal driver plus passenger ride comfort (solid lines) and 5\% decrease in ride comfort (dotted lines). 


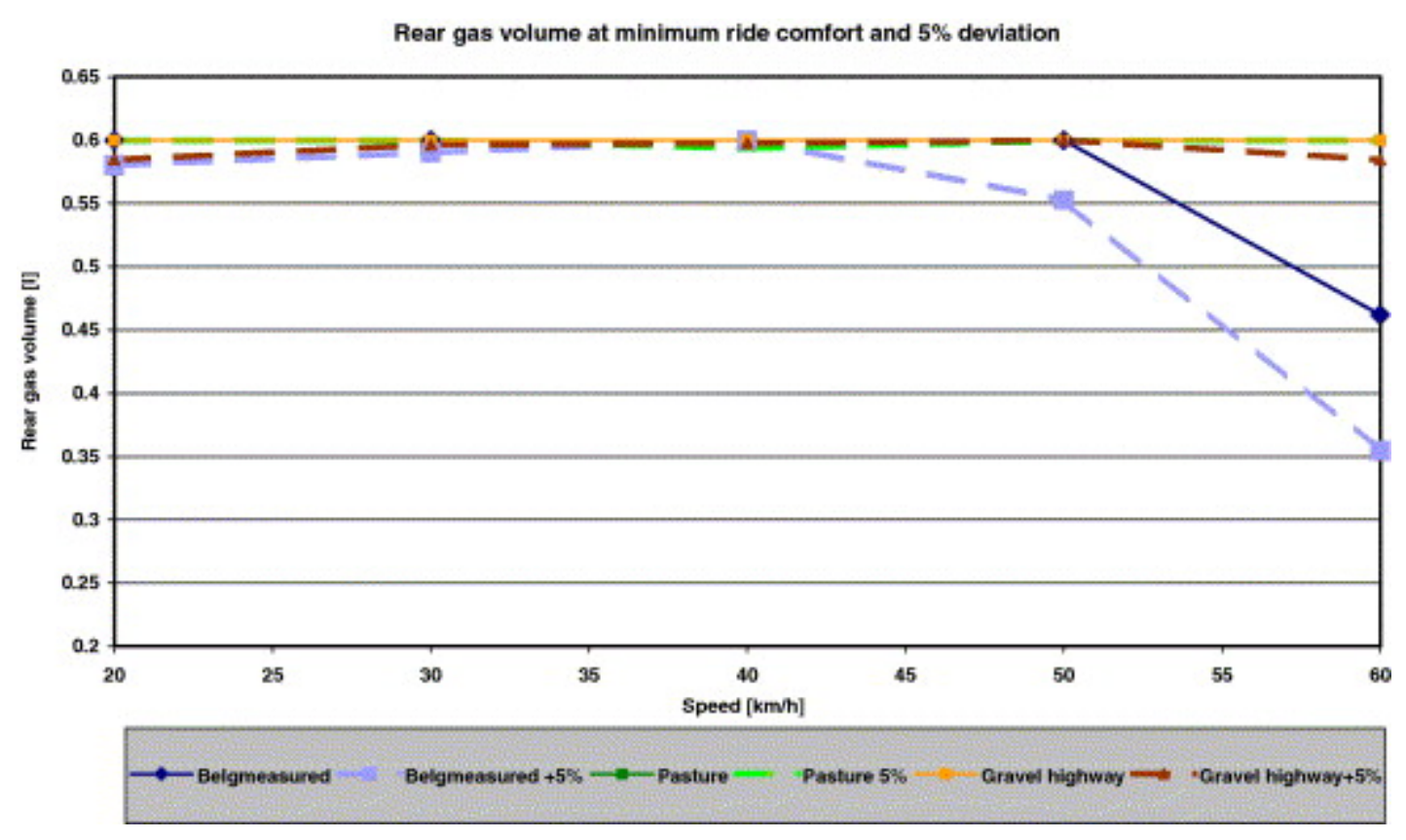

Fig. 17. Rear gas volume setting associated with optimal driver plus passenger ride comfort (solid lines) and 5\% decrease in ride comfort (dotted lines).

Percentage variation in the spring and damper values at 5\% decreased comfort over the minimum related values is listed in Table 7 . For speeds ranging from 10 to $50 \mathrm{~km} / \mathrm{h}$ the average deviation in front damping is $21 \%$, in rear damping $14 \%$, in front spring $11 \%$ and in rear spring $2 \%$. The effect is road and speed dependent. Ride comfort is thus less sensitive to variations in damper settings (especially the front damper) than to variations in spring settings with less sensitivity to front spring variations. The ride comfort is most sensitive to the rear suspension stiffness.

Table 7.

Percentage variation in damper and spring scaling factors for the $5 \%$ decreased comfort case as compared to the maximum comfort case

\begin{tabular}{|l|l|l|l|l|}
\hline Speed (km/h) & Damper front & Spring front & Damper rear & Spring rear \\
\hline 10 & 30 & -8 & -4 & -2 \\
\hline 20 & 13 & -13 & 8 & -2 \\
\hline 30 & 33 & -18 & 25 & -3 \\
\hline 40 & 17 & -6 & 24 & -2 \\
\hline 50 & 14 & -8 & 19 & -1 \\
\hline
\end{tabular}




\section{Conclusions}

Using driver ride comfort added to rear passenger comfort proves to be the best objective function for ride optimisation using a full vehicle simulation model. Optimisation of suspension settings for different roads and speeds to improve ride comfort results in considerable ride comfort improvements compared to the baseline value. Trends observed for the speeds considered indicate that using the optimised suspension setting obtained for one road at a particular speed will result in improved ride comfort on the track used for the optimisation at other speeds. Also, although the same improvement in ride comfort as could be obtained from optimisation of ride comfort for a specific track at various speeds cannot be achieved, ride comfort of any road at any speed is improved if the optimised value for one road and speed is used. The ride comfort is most sensitive to the rear suspension stiffness. Since the simulation model has not been refined to handle severe wheel hop induced by the road, results cannot necessarily be extended to higher speeds.

\section{References}

[1] International Standards Organisation. International standard mechanical vibration and shock - evaluation of human exposure to whole body vibration. 2nd ed., ISO 2631:Part 1, 1997-07-15.

[2] British Standard Institution. British standard guide to measurement and evaluation of human exposure to whole body mechanical vibration and repeated shock, BS 6841:1987. [3] P.S. Els, The applicability of ride comfort standards for off-road vehicles, $J$ Terramech 42 (2005), pp. 47-64.

[4] MSC.ADAMS: automatic dynamic analysis of multi-body systems, Version 12; 2002. [5] P.S. Els and P.E. Uys, Investigation of the applicability of the Dynamic-Q optimisation algorithm to vehicle suspension design, Math Comput Model 37 (2003), pp. 1029-1046. 
[6] P.S. Els, P.E. Uys, J.A. Snyman and M.J. Thoresson, Gradient-based approximation methods applied to the optimal design of vehicle suspension systems using computational models with severe inherent noise, Math Comput Model 43 (2006), pp. 787-801.

[7] Gobbi M, Francesco L, Ganpiero M. Multi-objective design of the suspension system of road vehicles. Paper \#61 In: Proceedings of the 18th IAVSD symposium, Kanagawa, Japan; August 2003.

[8] Eriksson P. Ride comfort optimization of buses. Doktorsavhandling vid Chalmers Tekniska Högskola; 2002.

[9] E.M. Elbeheiry and D.C. Karnopp, Optimal control of vehicle random vibration with constrained suspension deflection, J Sound Vib 189 (1996) (5), pp. 547-564. [10] I. Yoon and A. Hac, Semi-active suspensions with adaptive capability, J Sound Vib 180 (1995) (3), pp. 475-492.

[11] J. Marzaband, A. Goodarz, H. Zohoor and Y. Hojjat, Stochastic optimal preview control of a vehicle suspension, J Sound Vib 275 (2004), pp. 973-990.

[12] J.A. Tamboli and S.G. Joshi, Optimum design of a passive suspension system of a vehicle subjected to actual random road excitations, J Sound Vib 219 (1999) (2), pp. 193205.

[13] Z. Lozia, Analysis of vehicle behaviour during lane change manoeuvre on an uneven road surface, Vehicle Sys Dyn Suppl 20 (1991), pp. 417-431.

[14] International Standards Organisation. Mechanical vibration - road surface profiles reporting of measured data. ISO 8608; 1995.

[15] M. Gobbi, G. Mastino, C. Donisaelli, L. Gugulielmetto and E. Pisino, Optimal and robust design of a road vehicle suspension system, Vehicle Sys Dyn Suppl 33 (1991), pp. $3-22$.

[16] N. Ookubo, H. Moroizumi and K. Isoda, Handling characteristics on an uneven road surface in a turn. Technical note, JSAE Rev 21 (2000), pp. 241-263.

[17] M. Gobbi and G. Mastinu, Analytical description and optimisation of the dynamic behaviour of passively suspended road vehicles, J Sound Vib 245 (2001) (3), pp. 457481.

[18] M. Gobbi, G. Mastinu and C. Doniselli, Optimising a car chassis, Vehicle Sys Dyn 32 (1999), pp. 149-170. 
[19] N. Shieh, C. Lin, Y. Lin and K. Liang, Optimal design for passive suspension of a light rail vehicle using constrained multi-objective evolutionary search, J Sound Vib $\mathbf{2 8 5}$ (2005), pp. 407-424.

[20] K. Deprez, D. Mosho and H. Ramon, Comfort improvement of a nonlinear suspension using global optimization and in situ measurements, J Sound Vib 284 (2005), pp. 1003-1014.

[21] J.A. Snyman and A.M. Hay, The Dynamic-Q optimisation method: an alternative to SQP?, Comput Math Appl 48 (2004), pp. 549-560.

[22] http://www.armscorbusiness.com/SubSites/Gerotek/GEROTEK02_03_021.asp.

[23] Newel, R, Murphy JR. Further development in ride quality assessment. US Army Engineer Waterways Experiment Station, Vicksburg, Mississippi.

[24] Hall LC. Fundamentals of terramechanics \& soil vehicle interaction. Terrain profile characteristics. In: Proceedings of the wheels and tracks symposium, 9-11 September 1998. Cranfield University, UK.

Corresponding author. Tel.: +27 012 420225; fax: +27 0123625087 . 